\title{
GROUND DEFORMATION EXTRACTION USING VISIBLE IMAGES AND LIDAR DATA IN MINING AREA
}

\author{
Wenmin $\mathrm{Hu}^{\mathrm{a}, \mathrm{b}}$, Lixin $\mathrm{Wu}^{\mathrm{a}^{*}}$ \\ a IoT Perception Mine Research Center, China University of Mining and Technology, Xuzhou, 221008, China - huwm@cumt.edu.cn \\ ${ }^{\mathrm{b}}$ School of Environment Science and Spatial Informatics, China University of Mining and Technology, Xuzhou, 221116, China - \\ awulixin@263.net
}

\section{Commission VII, WG VII/5}

KEY WORDS: Ground Deformation, DEM, ZY-3 Stereo Images, LiDAR, Mining Area

\begin{abstract}
:
Recognition and extraction of mining ground deformation can help us understand the deformation process and space distribution, and estimate the deformation laws and trends. This study focuses on the application of ground deformation detection and extraction combining with high resolution visible stereo imagery, LiDAR observation point cloud data and historical data. The DEM in large mining area is generated using high-resolution satellite stereo images, and ground deformation is obtained through time series analysis combined with historical DEM data. Ground deformation caused by mining activities are detected and analyzed to explain the link between the regional ground deformation and local deformation. A district of covering $200 \mathrm{~km}^{2}$ around the West Open Pit Mine in Fushun of Liaoning province, a city located in the Northeast China is chosen as the test area for example. Regional and local ground deformation from 2010 to 2015 time series are detected and extracted with DEMs derived from ZY-3 images and LiDAR point DEMs in the case study. Results show that the mean regional deformation is $7.1 \mathrm{~m}$ of rising elevation with RMS $9.6 \mathrm{~m}$. Deformation of rising elevation and deformation of declining elevation couple together in local area. The area of higher elevation variation is $16.3 \mathrm{~km}^{2}$ and the mean rising value is $35.8 \mathrm{~m}$ with RMS $15.7 \mathrm{~m}$, while the deformation area of lower elevation variation is $6.8 \mathrm{~km}^{2}$ and the mean declining value is $17.6 \mathrm{~m}$ with RMS $9.3 \mathrm{~m}$. Moreover, local large deformation and regional slow deformation couple together, the deformation in local mining activities has expanded to the surrounding area, a large ground fracture with declining elevation has been detected and extracted in the south of West Open Pit Mine, the mean declining elevation of which is $23.1 \mathrm{~m}$ and covering about $2.3 \mathrm{~km}^{2}$ till 2015 . The results in this paper are preliminary currently; we are making efforts to improve more precision results with invariant ground control data for validation.
\end{abstract}

\section{INTRODUCTION}

As affected by mining disturbance, surface or ground deformation appears various forms including ground subsidence, collapse, slope sliding, buildings and landscape position changes etc. The mining disturbances not only appear in the active mining areas, but also expand to surrounding areas gradually. Local large deformation and regional slow deformation couple together. In order to predict and prevent the damages or disasters caused by ground deformation, it is necessary to monitor ground deformation process in high-resolution, good accuracy and small time intervals.

Recognition and extraction of mining ground deformation can help us understand the deformation process and space distribution, and estimate the deformation laws and trends. For the characteristics of periodic observation, wide coverage and higher plane positioning accuracy, high-resolution satellite remote sensing visible images can be used as data resource to detect the regional large deformation. These images provide

\footnotetext{
* Corresponding author.
} 
new choices in the measurement of ground deformation in mining area, while in-situ observation using triangulation, leveling and GPS measurements are costly and spatially limited. D-InSAR technique can be used to obtain small surface displacement, but large-scale deformation, such as ground collapse, will cause SAR images temporal decorrelation and it's difficult for phase unwrapping(Chen et al., 2013).

For monitoring in the area with acute landform changes, visible images especially the stereo images can provide visible features and also the 3D information of the surface. A method using SIFT features matching and measuring of high resolution satellite imagery had realized extensive landslide displacement field monitoring (Liu et al., 2015). The DEMs derived from high-resolution stereo satellite images had been used to detailed landslide hazard assessment and long time series of landform analysis (James et al., 2012; Nichol et al., 2006). However, its vertical positioning precision is not enough, and small local deformations are difficult to be discovered using visible images. LiDAR points can acquire dense point clouds for local area, and ground terrain model can be constructed with the points. Since the high vertical measurement accuracy, digital elevation model (DEM) derived from LiDAR points can be used to detect even slight deformation in local area.

In this paper, we extract the ground deformation using DEMs derived from ZY-3 satellite stereo images and LiDAR points in Fushun open pit mine. Large deformation has been detected in the active mining areas, and also the surrounding areas. The numerical results and distribution of deformation are discussed finally.

The rest of the paper is organized as follows. Section 2 is the introduction of study area and data used in our processing. Section 3 presents the method for ground deformation extraction using DEMs derived from the ZY-3 satellite stereo images and LiDAR points. Section 4 is the results and discussion of the experiment. Conclusions are given in Section 5.

\section{STUDY AREA AND DATA SETS}

\subsection{Overview of the Study Area}

The study area coving about $200 \mathrm{~km}^{2}$ is located in Fushun city with a coal mining history of more than 100 years in the Northeast China (Figure 1(a)). There are two open mine and three large waste rocks piling fields (Figure 1(b)). Among them, the West Open Mine is the largest opencast coal mine in Asia, with length of $6.6 \mathrm{~km}$, width of $2.2 \mathrm{~km}$ and depth of $500 \mathrm{~m}$ (Liu et al., 2015). As a result of extensive mining and inadequate treatment of coal mine waste rocks, ground deformation including landslides, subsidence, surface collapse and fracture have occurred since 1990s (Dong et al., 2009).

(a)

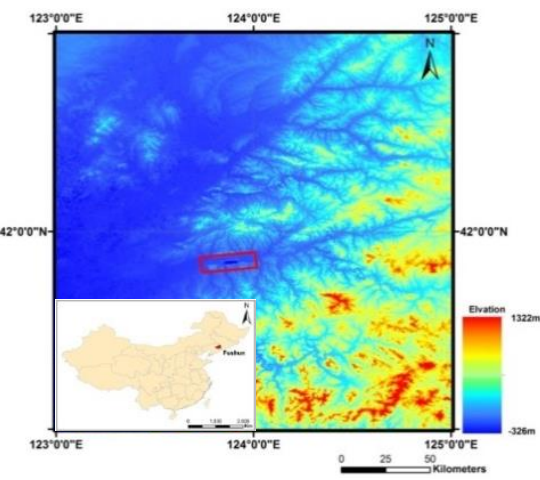

(b)

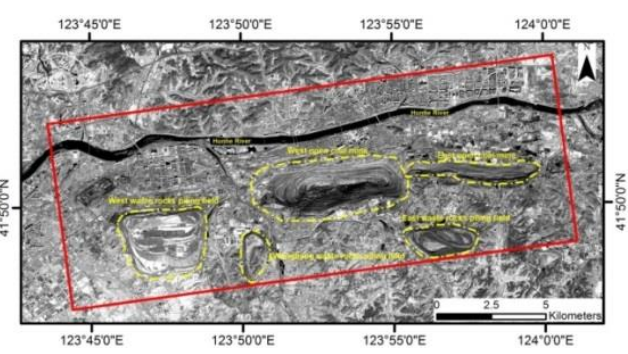

(c)

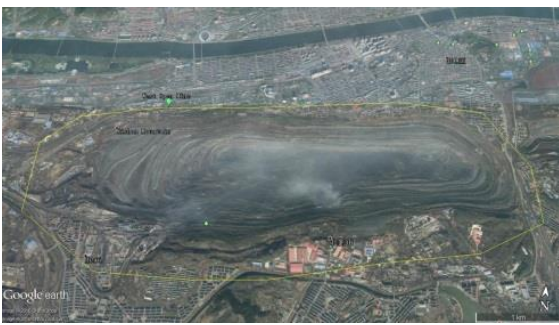

(d)

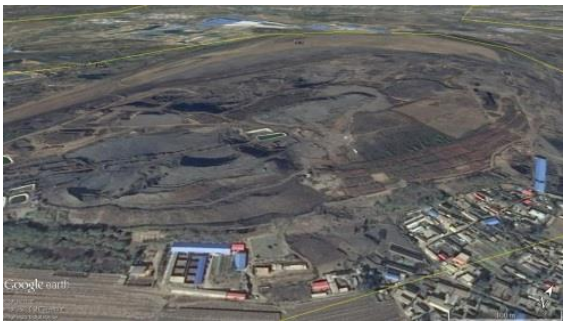

Figure 1 The location of Fushun study area. (a) ASTER GDEM of Fushun study area. The index map shows the location of Fushun city and the red rectangle is the study area. (b) ZY-3 image of Fushun study area (2015-10-24). The yellow dot dash lines show the main open mining areas and waste rocks piling fields in this area. (c) West Open Mine and (d) Wangliang Waste Rocks Piling Field from Google images. 


\subsection{Data Sets}

Ziyuan-3(ZY-3) surveying satellite which is launched on January 9, 2012, is the first civilian high-resolution stereo mapping satellite of China. It is equipped with 2 front and back view TDI CCD cameras with the resolution $3.5 \mathrm{~m}, 1$ Nadir view TDI CCD camera with the resolution $2.1 \mathrm{~m}, 1$ multispectral camera with the resolution $5.8 \mathrm{~m}$ and the width better than $50 \mathrm{~km}(\mathrm{Li}$ 2012; Tang et al., 2012). In this paper, the front-nadir-back stereo images are selected to derive the DEM in mining area. The acquisition times of the images were respectively on December 24, 2013, April 21, 2014 and October 24, 2015 ASTER DEM data is used as a base data for the ZY-3 imagery and also the benchmark of comparison with ZY-3 imagery derived DEMs at different time. 3D LiDAR points are actually measured by 3D laser scanning instruments respectively in November 2013 and August, 2014. The DEMs are used as the ground deformation extraction data source and also as the validation data for ZY-3 imagery derived DEMs (Table 1).

\begin{tabular}{|l|l|l|}
\hline Data resource & $\begin{array}{l}\text { Acquisition } \\
\text { time }\end{array}$ & $\begin{array}{l}\text { DEM spatial } \\
\text { resolution (m) }\end{array}$ \\
\hline \multirow{2}{*}{ ZY-3 stereo images } & $2013-12-24$ & $10 \mathrm{~m}$ \\
& $2014-04-21$ & $10 \mathrm{~m}$ \\
ASTER GDEM & $2015-10-24$ & $10 \mathrm{~m}$ \\
LiDAR Points & $2010-7$ & $30 \mathrm{~m}$ \\
& $2013-11$ & $0.5 \mathrm{~m}$ \\
\hline
\end{tabular}

Table 1 Data sets used in this paper.

\section{METHOD}

The main procedure of ground deformation extraction using visible images and liDAR data in mining area is indicated in Figure 2. DEM extraction process with ZY-3's three-line-array images is mainly finished in ERDAS IMAGE 2013 using the LPS tool, and LiDAR DEMs are derived from the scanning point clouds. After co-registration of spatial resolution and location, all the DEMs from ZY-3 images are compared with ASTER GDEM which is used as a reference. Through the recognition of elevation variations, the districts of deformation are detected and extracted automatically. Regional, typical areas and profiles comparisons are used to analyze the deformation distribution and trends. The results are validated by LiDAR DEMs which are in high precision.

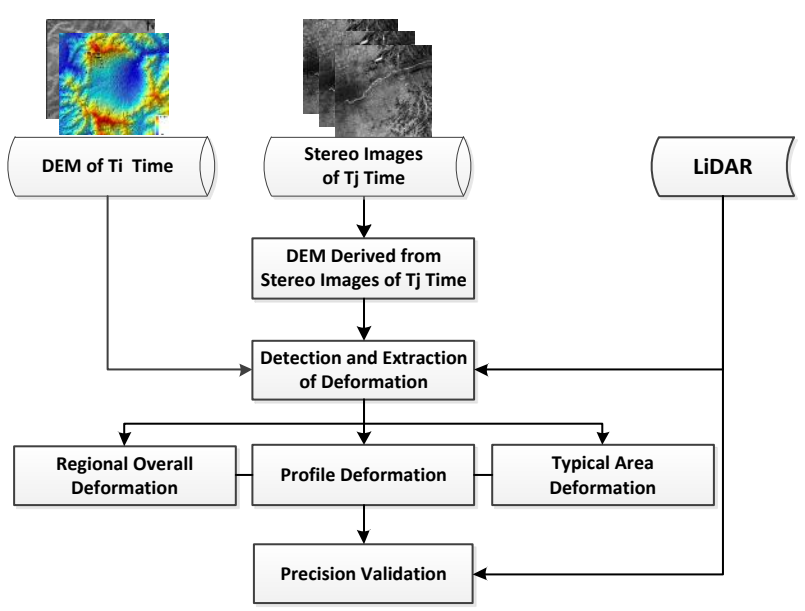

Figure 2 The main procedure of ground deformation extraction using visible images and liDAR data.

\section{RESULTS AND DISCUSSION}

\subsection{Regional Overall Deformation}

Figure 3 shows the DEMs from ASTER GDEM and ZY-3 stereo images in the study area. Table 2 is the statistical results of multi-temporal Elevations. It is obviously found that the minimum elevation rises quickly from $326.0 \mathrm{~m}$ to $-126.1 \mathrm{~m}$ as time goes on while the other parameters change slightly. Figure 4 shows the overall ground deformation using the elevation differencing between ZY-3 DEMs and ASTER GDEM. Table 3 displays the statistical results of elevation changes. Form Table 3, Elevations from ZY-3 DEMs are higher than ASTER GDEM, the mean elevation changes has been increased by $11.9 \mathrm{~m}$, $17.1 \mathrm{~m}$ and $7.1 \mathrm{~m}$ in 2013, 2014 and 2015 respectively. Due to the backfilling process while mining in this area, there are over hundred meters deformation especially in the active mining area, where the slope declines steeply and the pit backfill rises on the other hand (white polygon in Figure 4)

(a)

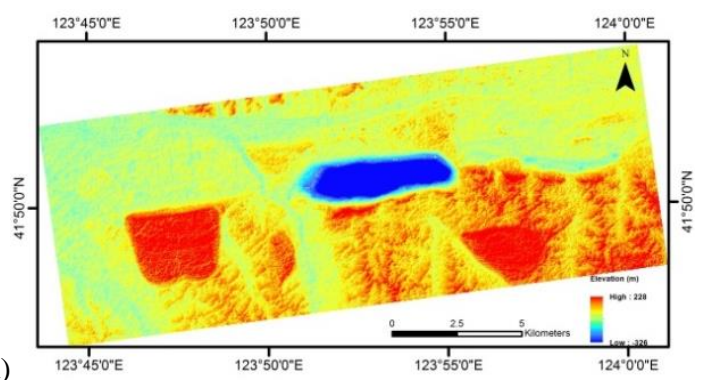


(b)

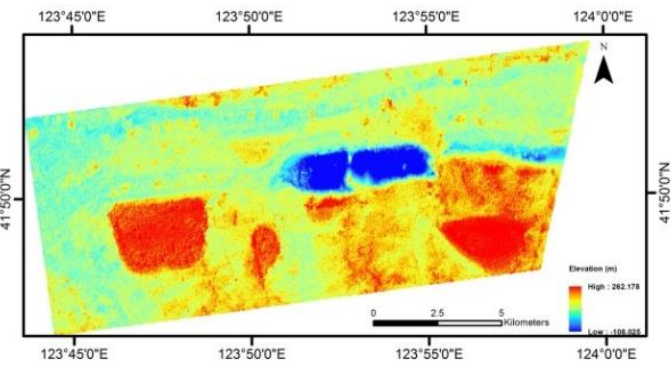

(c)

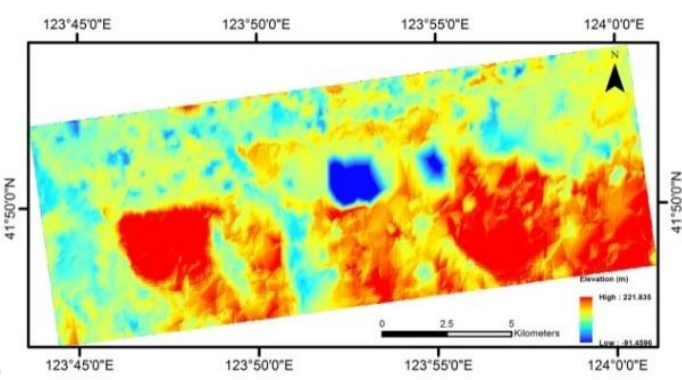

(d)

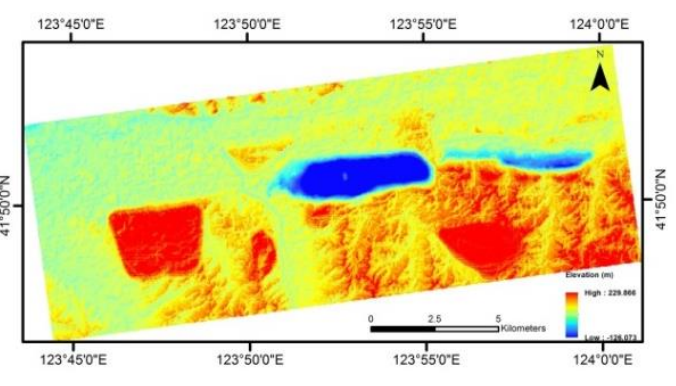

Figure 3 DEM in the study area. (a) ASTER GDEM; (b) ZY-3 DEM in 2013; (c) ZY-3 DEM in 2014; (d) ZY-3 DEM in 2015.

\subsection{Typical Areas Deformation}

Typical areas of mining pits and piling fields displayed in Figure 1 are chosen to make a detailed analysis using ZY-3 DEM in 2015 and ASTER GDEM. Table 4 is the statistical results of deformation in typical areas. East Open Mine is the only region where the deformation of elevation is lower $1.4 \mathrm{~m}$ for its mining activity. Since the mining reduction and backfilling, deformation of elevation in West Open Mine is increased by $26.5 \mathrm{~m}$ on average. Elevations in waste rocks piling fields all raise with average values $11.0 \mathrm{~m}, 21.8 \mathrm{~m}$ and $18.2 \mathrm{~m}$ respectively.

For more detailed distribution, we extract the areas with rising and declining elevation deformation. Figure 5 and Figure 6 display the distribution of deformation areas with rising elevations (red polygons) and declining elevations (green polygons); both of them are located in or near the typical areas. Table 5 and Table 6 are the statistical results of the deformation areas.

From the distribution, waste rocks piling fields show a deformation of rising elevations, while deformation of rising and declining elevations couple together in active mining areas (West Open Mine and East Open Mine). For example, Number 1 district of Figure 5 in West Open Mine shows the deformation with mean rising elevation $75.0 \mathrm{~m}$. At the same time, Number 1 and 2 districts of Figure 6 indicate the declining deformation with mean values $14.9 \mathrm{~m}$ and $23.1 \mathrm{~m}$ in north and south slopes respectively. Since 2010, in Qiantai mountain district of the West Open Mine's south slope, a ground fracture with a length of about $3100 \mathrm{~m}$ has appeared. In June 2014, the fracture reached a width of $40 \mathrm{~m}$ with the maximum drop of over $18 \mathrm{~m}$ (Liu et al., 2015). Figure 6 also extracts the ground fracture (Number 2-West Open Mine-South in Table 6), the mean declining elevation of which is $23.1 \mathrm{~m}$ and covering about $2.3 \mathrm{~km}^{2}$.

(a)

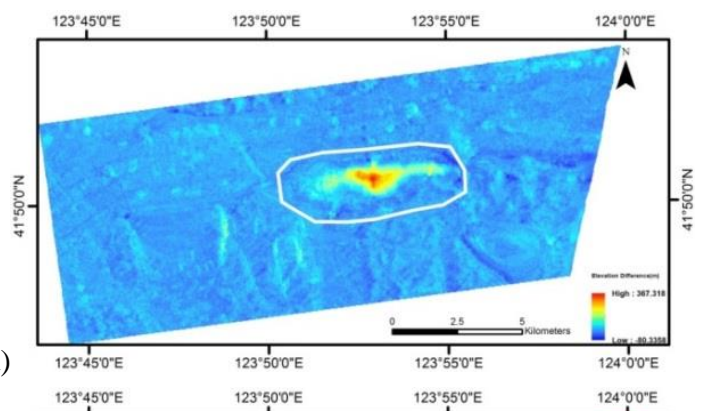

(b)

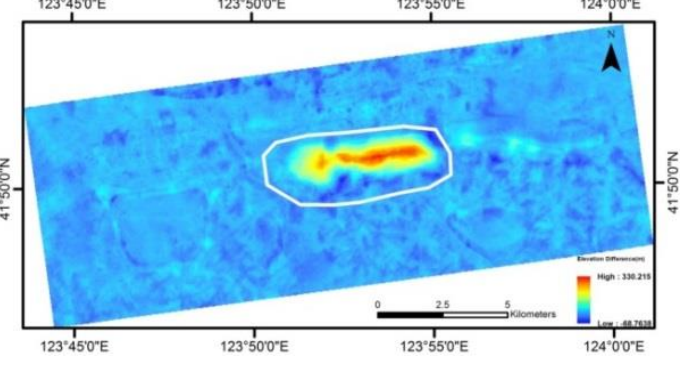

(c)

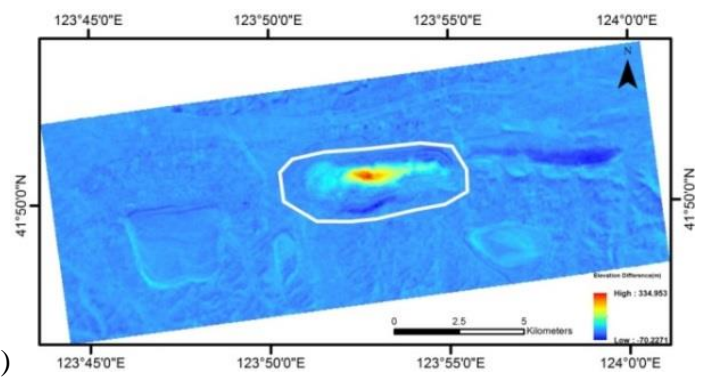

Figure 4 Elevation changes between ZY-3 DEMs and ASTER GDEM. (a) ZY-3 DEM in 2013 and ASTER GDEM; (b) ZY-3 DEM in 2014 and ASTER GDEM; (c) ZY-3 DEM in 2015 and ASTER GDEM. 


\begin{tabular}{|l|l|l|l|l|l|}
\hline Time & Data Source & Minimum $(\mathrm{m})$ & Maximum $(\mathrm{m})$ & Mean $(\mathrm{m})$ & Standard Deviation $(\mathrm{m})$ \\
\hline $2010-07$ & ASTER GDEM & -326.0 & 228.0 & 90.8 & 50.2 \\
$2013-12-24$ & ZY-3 DEM & -108.0 & 262.2 & 107.6 & 41.2 \\
$2014-04-21$ & ZY-3 DEM & -91.5 & 221.8 & 115.8 & 34.3 \\
$2015-10-24$ & ZY-3 DEM & -126.1 & 229.9 & 101.2 & 42.4 \\
\hline
\end{tabular}

Table 2 Results of multi-temporal DEMs in the study area.

\begin{tabular}{|l|l|l|l|l|}
\hline Data sets & Minimum $(\mathrm{m})$ & Maximum $(\mathrm{m})$ & Mean $(\mathrm{m})$ & Standard Deviation $(\mathrm{m})$ \\
\hline 2013 ZY-3 DEM and ASTER GDEM & -80.3 & 367.3 & 11.9 & 12.6 \\
2014 ZY-3 DEM and ASTER GDEM & -68.8 & 330.2 & 17.1 & 16.9 \\
2015 ZY-3 DEM and ASTER GDEM & -71.1 & 335.0 & 7.1 & 9.6 \\
\hline
\end{tabular}

Table 3 The statistical results of elevation changes between ZY-3 DEMs and ASTER GDEM.

\begin{tabular}{|l|l|l|l|l|l|l|}
\hline \multirow{2}{*}{ Number } & Name of Typical Area & \multicolumn{3}{|l|}{ Parameters of the Deformation of Elevation $(\mathrm{m})$} & \multirow{2}{*}{$\begin{array}{l}\text { Area } \\
\left(\mathrm{km}^{2}\right)\end{array}$} \\
\cline { 3 - 6 } & & Minimum & maximum & Mean & Standard Deviation & \\
\hline 1 & West Open Mine & -71.1 & 334.9 & 26.5 & 50.8 & 17.0 \\
3 & East Open Mine & -65.1 & 54.1 & -1.4 & 28.2 & 4.7 \\
4 & West Waste Rocks Piling Field & -37.0 & 64.8 & 11.0 & 10.8 & 10.9 \\
5 & East Waste Rocks Piling Field & -15.7 & 61.9 & 21.8 & 10.7 & 4.0 \\
& Wangliang Waste Rocks Piling & -15.1 & 50.0 & 18.2 & 10.4 & 2.4 \\
\hline
\end{tabular}

Table 4 Results of the deformation in typical areas with ZY-3 DEM in 2015 and ASTER GDEM.

\begin{tabular}{|l|l|l|l|l|}
\hline Number & Name of Areas with Rising Elevation & $\begin{array}{l}\text { Mean Rising } \\
\text { Elevation(m) }\end{array}$ & $\begin{array}{l}\text { Standard Deviation of } \\
\text { Rising Elevation(m) }\end{array}$ & $\begin{array}{l}\text { Area } \\
\left(\mathrm{km}^{2}\right)\end{array}$ \\
\hline 1 & West Open Mine & 75.0 & 64.3 & 7.0 \\
2 & North outside East Open Mine & 24.7 & 2.6 & 0.5 \\
3 & East Open Mine- south & 28.9 & 6.8 & 2.3 \\
4 & West Waste Rocks Piling Field & 30.5 & 8.8 & 1.8 \\
5 & Wangliang Waste Rocks Piling Field & 26.8 & 4.9 & 1.5 \\
6 & East Waste Rocks Piling Field & 28.8 & 6.7 & 3.2 \\
The Overall values of Rising Elevation & 35.8 & 15.7 & 16.3 \\
\hline
\end{tabular}

Table 5 Results of the deformation areas with rising elevation using ZY-3 DEM in 2015 and ASTER GDEM.

\begin{tabular}{|l|l|l|l|l|}
\hline Number & $\begin{array}{l}\text { Name of Areas with Declining } \\
\text { Elevation }\end{array}$ & $\begin{array}{l}\text { Mean Declining } \\
\text { Elevation }(\mathrm{m})\end{array}$ & $\begin{array}{l}\text { Standard Deviation of } \\
\text { Rising Elevation }(\mathrm{m})\end{array}$ & $\begin{array}{l}\text { Area } \\
\left(\mathrm{km}^{2}\right)\end{array}$ \\
\hline 1 & West Open Mine-North & -14.9 & 7.9 & 1.2 \\
3 & West Open Mine-South & -23.1 & 14.6 & 1.1 \\
4 & East Open Mine & -28.2 & 14.8 & 2.7 \\
5 & West Waste Rocks Piling Field & -12.8 & 5.6 & 0.9 \\
6 & South outside East Open Mine & -11.8 & 5.8 & 0.5 \\
\multicolumn{2}{|l|}{ The Overall values of Declining Elevation } & -17.6 & 7.1 & 0.4 \\
\hline
\end{tabular}

Table 6 Results of the deformation areas with declining elevation using ZY-3 DEM in 2015 and ASTER GDEM. 


\begin{tabular}{|l|l|l|l|l|}
\hline \multirow{2}{*}{ Data sets } & \multicolumn{2}{|l|}{ Elevation Variation $(\mathrm{m})$} & $\begin{array}{l}\text { Rising Area } \\
\left(\mathrm{km}^{2}\right)\end{array}$ & $\begin{array}{l}\text { Declining } \\
\text { Area }\left(\mathrm{km}^{2}\right)\end{array}$ \\
\cline { 2 - 5 } & Mean & Standard Deviation & 2.6 & 3.1 \\
\hline LiDAR DEM of 2014 and 2013 & 1.5 & 3.6 & 7.0 & 3.3 \\
\hline
\end{tabular}

Table 7 The deformation results using LiDAR DEMs and ZY-3 DEMs in West Open Mine.

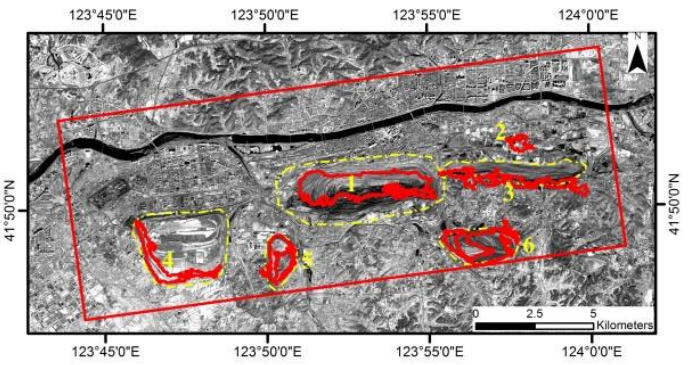

Figure 5 Distribution of deformation areas with rising elevation using ZY-3 DEM in 2015 and ASTER GDEM.

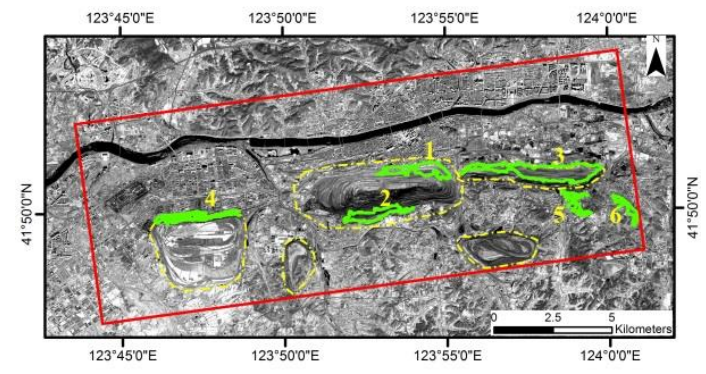

Figure 6 Distribution of deformation areas with declining elevation using ZY-3 DEM in 2015 and ASTER GDEM.

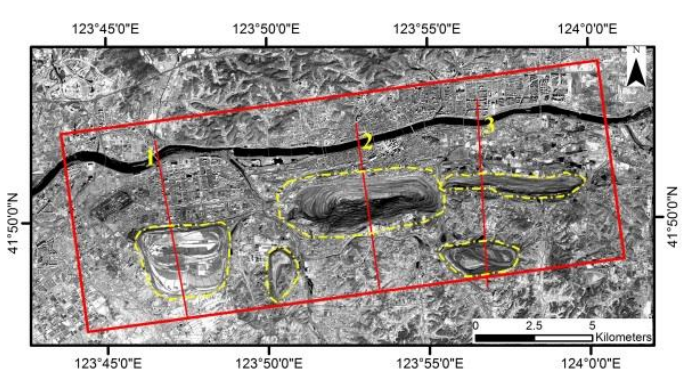

Figure 7 Location of three profiles in this area. Profile 1 crosses West Waste Rocks Piling Field; Profile 2 crosses the West Open Mine; Profile 3 crosses East Open Mine and East Waste Rocks Piling Field.

\subsection{Profiles Deformation}

We also extract three north-south profiles (Figure 7) across the study areas to map vertical displacements along the profiles (Figure 8). For profile 1, the elevation level in West Waste
Rocks Piling Field is rising. From profile 2, the elevation level in West Open Mine is rising too, but with more complicated deformation. A large landslide in the north slope of the mine pit occurred as displayed in topographic profile of 2015. At the same time, the south edge of mining area has been moving to south further, the south slope appears declining deformation which is also corresponding to the results in

Figure 6. Profile 3 also shows the declining deformation in East Open Mine and rising elevation level in East Waste Rocks Piling Field, which demonstrates the similar results in 4.2.

(a)
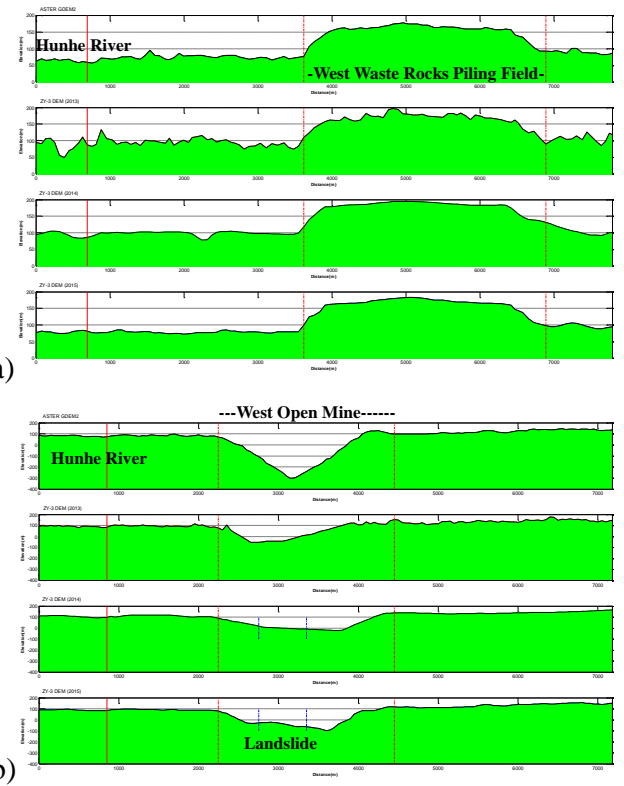

(b)

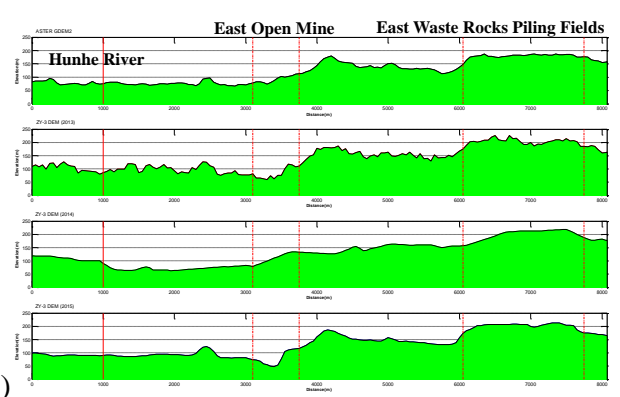

Figure 8 Topographic profiles derived from ASTER GDEM, ZY-3 DEM 2013, 2014, 2015 respectively. (a) Profile 1. (b) Profile 2. (c) Profile 3. 


\subsection{Deformation from LiDAR DEMs}

Figure 9 shows the results of deformation extraction in West Open Mine using the LiDAR DEMs acquired in November 2013 and August 2014. The range of elevation deformation is from $-67.5 \mathrm{~m}$ to $58.0 \mathrm{~m}$. An average elevation change is $1.5 \mathrm{~m}$ and the RMS is $3.6 \mathrm{~m}$. Deformation with rising or declining elevation couples together and has been extracted in Figure 9 (d). The area of deformation with rising elevation is $2.6 \mathrm{~km}^{2}$ (dark red area), and the decline area with elevation variation more than $2 \mathrm{~m}$ is $2.2 \mathrm{~km}^{2}$ (blue area), A slight decline area with elevation variation less than $2 \mathrm{~m}$ is about $0.9 \mathrm{~km}^{2}$ (green area). Table 7 is statistical results of deformation using LiDAR DEMs in West Open Mine. Although the lowest elevation is lower than the ZY-3 DEMs and near the value of ASTER GDEM, the distribution of deformation is consistent with the results above in 4.2. Compared with the results from 2015 ZY-3 DEM and ASTER GDEM, it can be inferred that elevation rising area is enlarging quickly for the artificial backfill process, but elevation declining area is increasing slowly too for the slow deformation of slope sliding.

\section{CONCLUSIONS}

Ground deformation is detected and extracted using ZY-3 stereo images derived DEMs, ASTER GDEM, and LiDAR DEMs. Regional overall deformation, typical area deformation and topographical profiles deformation have been used to analyze the distribution and trends. Application in Fushun case study indicates that:

(1) Ground deformation especially the acute deformation such as large fracture or landslide can be monitoring using visible stereo images. The experiments using ZY-3 stereo images derived DEMs in this paper present a preliminary results of deformation analysis in mining area.

(2) Deformation of rising and declining elevation couples together in active mining area. And that the ground deformation caused by mining activities has expanded from local deformation to regional ground deformation.

(3) The numerical results of deformation need more precise ground control data for validation. Multi-temporal and multi-resources of satellite visible stereo images, LiDAR data, and others can provide more detailed information. However, as affected by mining disturbance, the validation data should be with invariant features and location.
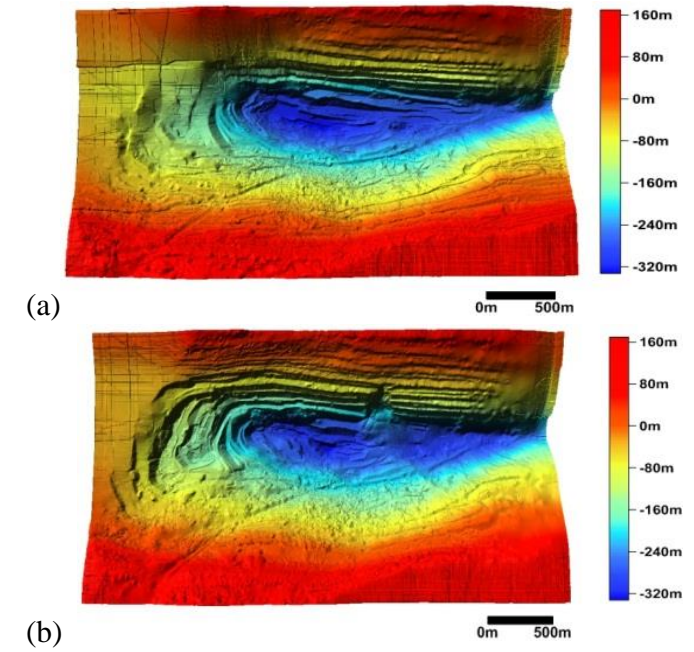

(c)

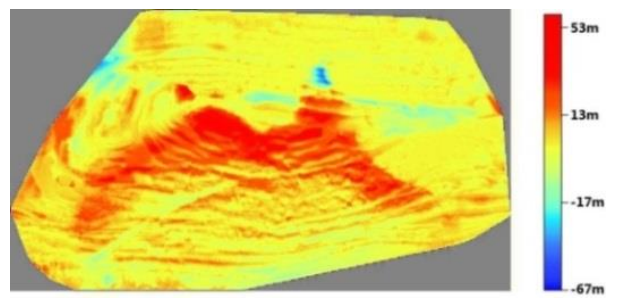

(d)

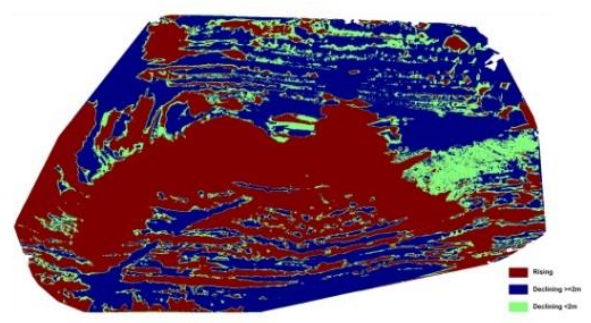

Figure 9 Deformation extraction using LiDAR DEMs in 2013 and 2014 in the case study. (a) LiDAR DEM of November 2013; (b) LiDAR DEM of August 2014; (c) Deformation from 2013 to 2014; (d) Distribution of deformation with rising or declining elevation.

\section{ACKNOWLEDGEMENTS}

This research was funded by Natural Science Foundation of Jiangsu Province of China (No.BK20140186), Foundation of China University of Mining and Technology (No. 2014QNB43) and Postdoctoral Science Foundation of Jiangsu Province of China (No.1401053B).

\section{REFERENCES}

[1] Chen, B., Deng, K., Fan, H., and Hao, M. 2013. Large-scale deformation monitoring in mining area by D-InSAR and 3D laser scanning technology integration. International Journal of Mining Science and Technology 
23, pp. 555-561.

[2] Dong, Y., Fu, B., and Ninomiya, Y. 2009. Geomorphological changes associated with underground coal mining in the Fushun area, northeast China revealed by multitemporal satellite remote sensing data. International Journal of Remote Sensing 30, pp. 4767-4784.

[3] James, L. A., Hodgson, M. E., Ghoshal, S., and Latiolais, M. M. 2012. Geomorphic change detection using historic maps and DEM differencing: The temporal dimension of geospatial analysis. Geomorphology 137, pp. 181-198.

[4] Liu, S., Wang, H., Huang, J., and Wu, L. 2015. High-resolution remote sensing image-based extensive deformation-induced landslide displacement field monitoring method. International Journal of Coal Science \& Technology 2, pp. 170-177.

[5] Nichol, J. E., Shaker, A., and Wong, M.-S. 2006. Application of high-resolution stereo satellite images to detailed landslide hazard assessment. Geomorphology 76, 68-75.

[6] Li, D., 2012. China's first civilian three-line-array stereo mapping satellite: ZY-3. Acta Geodaetica et Cartographica Sinica 41, pp. 317-322.

[7] Tang, X., Zhang, G., Zhu, X., Pan, H., Jiang, Y., Zhou, P., and Wang, X., 2012. Triplelinear-array imaging geometry model of Ziyuan-3surveying satellite and its validation. Acta Geodaetica et Cartographica Sinica 41, pp. 191-198. 